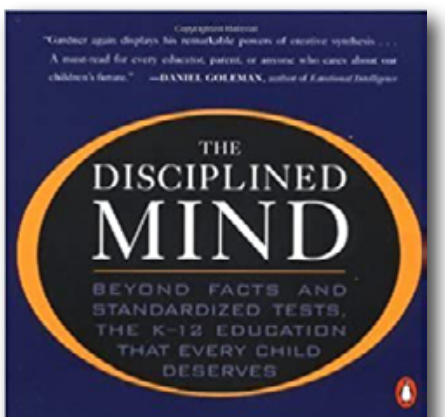

Howard Gardner

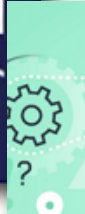

RESENHA DAS OBRAS

GARDNER, Howard. The disciplined mind:

beyond facts and standardized tests $\mathrm{K}-12$

education that every child deserves. New York,

Penguin Books, 2000.

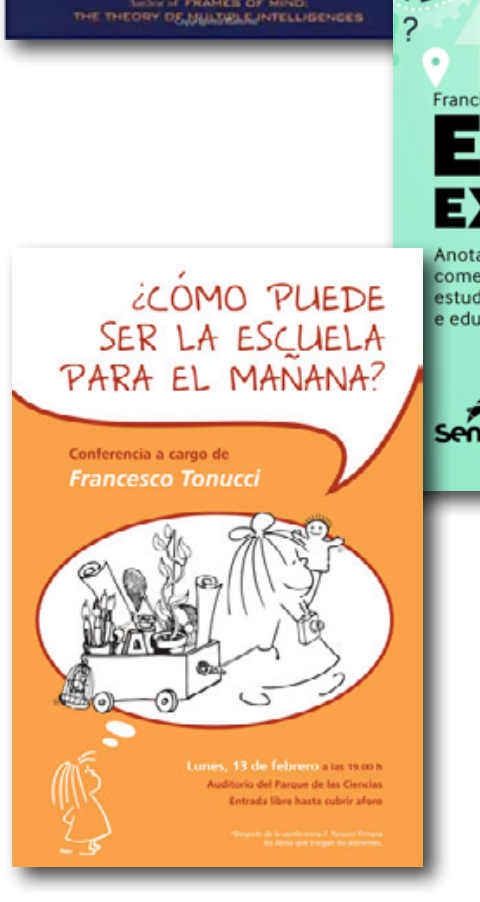

¿Cómo puede ser la escuela para el mañana? Granada:

Parque de las Ciencias de Granada, 20 fev. 2012. 1 vídeo

(80 min.). Disponível em: https://www.youtube.com/

watch?v=caS8XeuCPFA. Acesso em: 10 dez. 2020.

\title{
Educação de qualidade
}

Você e eu somos a favor da educação de qualidade. E não estamos sozinhos, todas as pessoas que conhecemos também o são. E, apesar dessa unanimidade, poucos são os casos de educação de qualidade aceitos pela maioria. Como explicar tão grande acordo, seguido por desacordos?

Há muitas explicações para o paradoxo apontado no parágrafo anterior. Uma delas é a função fática da linguagem. Tal função comunicativa procura "manter a coesão no interior dos grupos" (LEECH, 1977, p. 81). O discurso fático diz tudo e nada diz. 
Ele utiliza referências cujo significado é tão amplo que tem unânime concordância dos ouvintes. É muito utilizado por políticos. Leech exemplifica a função fática a partir do discurso de posse de John Kennedy. O presidente americano dirige-se à nação fazendo declarações com as quais todos concordam, mas o que ele diz não é informativo. É um conjunto de generalidades que os ouvintes, de qualquer espectro ideológico, aceitam como desejável. Convém citar alguns trechos do discurso de Kennedy:

[...] celebramos hoje não a vitória de um partido, mas uma comemoração da liberdade, que simboliza um fim e um começo, que significa reafirmação e mudança. [...] 0 mundo é agora muito diferente: o homem tem em suas mãos o poder necessário para acabar com todas as formas da miséria humana e com todas as formas de vida humana (LEECH, 1977, p. 84).

Nos curtos trechos que citei, Kennedy fala de uma liberdade que é fim e começo, reafirmação e mudança. Diz que o homem agora tem o poder de acabar com todas as misérias, assim como findar todas as formas de vida humana. Discurso político recheado com tais afirmações é feito para conquistar a maioria. Liberdade é um valor para todos. E todos entendem que é possível acabar com a miséria. Mas essas afirmações não geram compromisso. Elas têm significado difuso ou até mesmo nenhum significado.

Volto ao tema dessa resenha, educação de qualidade. É possível pensar um discurso recheado de proposições fáticas sobre ele. É possível imaginar um político discursando sobre educação com qualidade, recebendo apoio de todos os ouvintes e, ao mesmo tempo, nada comunicando de significativo. 0 resultado disso é que se repetem falas sobre qualidade, mas a educação continua a ser uma atividade social muito criticável por causa da precariedade de seus processos e resultados. E as críticas também, muitas vezes, acabam sendo comunicadas na forma de declarações fáticas com as quais todos concordam, mas não oferecem direção para a ação porque seu significado é vazio.

Se tentarmos ultrapassar o discurso fático, descobriremos que qualidade não tem o mesmo significado para todos. Ou, em outras palavras, há diversos sentidos de educação de qualidade que precisam ser explicitados para fundamentar críticas e propostas. Escolhi duas obras para mostrar como a educação de qualidade pode ser entendida: Ensino excelente, de Francisco de Moraes, e The Disciplined Mind, de Howard Gardner. São livros que abordam qualidade de maneira bastante diferente, embora seja possível perceber algumas coincidências de pontos de vista entre os dois autores. No processo de preparar a resenha, entendi que seria enriquecedor considerar mais um autor, Francesco Tonucci. Neste último caso, a obra não é livro, mas o vídeo de uma palestra que o grande educador italiano fez sobre o tema "¿Cómo puede ser la escuela para el mañana?". Lembrei-me de Tonucci porque ele oferece alguns contrapontos interessantes a ideias propostas por Moraes e Gardner. 


\section{Escola de hoje e escola de amanhã}

O título da palestra de Tonucci, ¿Cómo puede ser la escuela para el mañana?, não foi escolhido pelo autor, mas proposto pelos organizadores do evento. A proposta sugeria que o educador italiano descrevesse como deveria ser a escola do futuro. Implicitamente, o que os organizadores queriam era ouvir um discurso otimista sobre o futuro e, ao mesmo tempo, uma crítica sobre o presente. Tonucci não fez o esperado. Ele se recusou a delinear um quadro futurista, pois, na sua opinião, a escola que queremos para o futuro tem que ser concretizada agora no presente. Essa é uma abordagem interessante sobre qualidade. Muitos pensam que a qualidade desejada é um projeto para o futuro, apoiado por muita tecnologia e ciência. Mas, para Tonucci, a urgência de uma escola decente (de qualidade) não comporta espera.

Tonucci começa sua conversa observando que, se a escola que temos não é boa para o amanhã, também não é boa para hoje. Em outras palavras, ele sugere que é preciso ter já a escola ideal, em vez de projetar desejos de melhoria para o futuro. A seguir, o educador italiano lembra que a crítica que se faz à escola de hoje tem como base uma idealização da escola de ontem, uma escola para poucos e que expulsava, no processo, as crianças das classes populares. O mecanismo da escola para poucos tinha como base uma educação que pressupunha o saber desenvolvido nos ambientes familiares de classe média. Crianças com tal origem vinham à escola para complementar a educação que já haviam desenvolvido. Essa é uma educação para quem sabe, não é uma educação para quem tudo desconhece, inclusive a linguagem dos professores. 0 autor examina, com exemplos, a situação de uma escola aparentemente democrática, mas que afasta todos aqueles que nela comparecem sem capital cultural. Essa escola, que foi a de Tonucci na infância e adolescência, é vista saudosamente como uma instituição de sucesso. Ela era muito adequada para os filhos das classes médias, porém expulsava, por meio de repetências e/ou desinteresse, os filhos das classes populares. Infelizmente, diz o autor, a escola que temos ainda é apenas para quem sabe. Observo, de maneira incidental, que continuamos a considerar certas escolas do passado uma referência de qualidade em educação. Mas essas escolas jamais passariam pelo teste de ensinar quem não sabe, nos termos da análise do educador italiano.

Tonucci insiste. Diz que precisamos de uma escola para todos. Precisamos de uma escola que ajude os alunos que nada sabem, porque suas famílias não dominam a cultura que normalmente é a porta de entrada para a ação dos educadores. Essa ideia muda o sentido da inclusão. Não se trata apenas de acolher as crianças que nada sabem. Essas crianças precisam de mais cuidado, e não apenas frequentar salas de aula. Precisam superar o profundo fosso que as separa das crianças das classes privilegiadas. Embora não fale em qualidade nesse ponto, o autor sugere que a excelência da educação existirá quando a escola oferecer oportunidade para que todos os alunos aprendam, mesmo que nada tragam de suas casas. 
Tonucci sugere alguns princípios a considerar:

A escola deve oferecer bases culturais para todos os alunos. Reitera-se aqui um aspecto que já comentei: a obrigação das instituições escolares em educar aqueles que nada sabem.

A escola deve ser um ambiente bonito e rico. Nada de improvisos. Nada de adaptações. Nada daqueles escolões com espaços imensos e opressivos. É preciso que a escola seja acolhedora, rica em estímulos, e não um local cinzento, desagradável, massificante. Tonucci se perfila com os educadores que consideram a arquitetura escolar um elemento fundamental na educação. Como veremos mais à frente, Gardner ressalta esse ponto de maneira muito concreta, ao abordar as escolas de Reggio Emilia, locais de muito conforto e beleza para as crianças.

A escola deve ser um local de abertura. Para Tonucci, abertura significa capacidade de escutar. Escutar os alunos. Escutar o que as crianças trazem para a escola. Isso é diferente do velho pressuposto que predominava (e talvez ainda predomine) nas instituições escolares: de que compete à escola complementar uma cultura que os alunos já elaboraram no lar.

A escola deve desenvolver o melhor de cada aluno. Todos podem ser excelentes em algo. Cabe à escola descobrir isso e assegurar-se de que seus alunos sejam excelentes em algo de que gostem e no qual mergulhem com vontade. Gardner, com outras palavras e fundamentos, acaba dizendo o mesmo.

A mão deve estar presente em todos os níveis de ensino. Tonucci diz que, na escola que temos, o trabalho manual vai desaparecendo à medida que se avança na educação. E, nos anos finais, nada mais há de manual na escola. No entanto, a mão é um elemento fundamental de exploração do mundo, de aventura de aprender em todas as idades. Moraes ressalta esse princípio em sua obra, lembrando que a mão educa o cérebro.

Felicidade é uma meta necessária em educação. Além de favorecer o desenvolvimento em cada um, a escola deve nos tornar felizes. A partir do tema felicidade, Tonucci faz uma crítica a abordagens economicistas que dizem que a escola tem que olhar para o mercado. Gente feliz saberá encontrar caminhos em termos de trabalho. Por outro lado, gente supostamente qualificada, mas infeliz, vive uma tragédia, pois odeia o que faz.

A escola deve educar cientificamente. E deve fazer isso pela busca, não pela transmissão da verdade previamente empacotada. A educação deve ser investigativa, não dogmática. Há, aqui, outra ponte entre Tonucci e Gardner.

A escola deve ser divergente. E a escola mais diversa é a pública. Como a diversidade é importante para formar cidadãos que entendam o mundo em que vivem, qualquer escola pública é a melhor opção. Além disso, o autor comenta algumas práticas que estão na contramão da diversidade - uma delas é a de separar em grupos especiais alunos com algum tipo de problema. Toda essa segregação ocorre por causa do pensamento dominante da escola para iguais. A última linha de 
defesa da escola dos iguais é a formação de grupos por idade. Essa escola seriada impede a cooperação entre alunos de diferentes níveis. Tonucci usa o termo diversidade com muitas facetas. Embora ele não aborde todas elas, a gente pode inferir que a diversidade abrange gênero, etnia, idade, origem social, econômica e cultural, dialetos, linguagens e muito mais. A escola precisa ser diversa como o mundo.

As propostas de Tonucci definem educação de qualidade em direções contrárias ao entendimento de muitas pessoas. Elas mostram que é preciso agregar significados à aparente concordância de que todos são a favor da qualidade. Creio que os comentários do educador italiano são uma introdução interessante para a minha apreciação das duas obras que vêm a seguir.

\section{Educação orientada pela verdade, beleza e bondade}

Gardner, para dar concretude às suas propostas sobre educação, sugere que as escolas devem voltar-se para três valores fundamentais: verdade, beleza e bondade. 0 autor reconhece que tais valores sofrem atualmente ataques frequentes do pós-modernismo e do relativismo. Mesmo assim, ele insiste em suas propostas e escolheu três exemplos que podem clarear mais o que propõe. No campo da verdade, sugere estudos aprofundados sobre teoria da evolução. Sobre beleza, recomenda apreciação da obra de Mozart, mais particularmente da ópera O casamento de Fígaro. Já na esfera da bondade, propõe uma avalição do que ocorreu no Holocausto e das consequências desse horroroso episódio da História. Esses três exemplos poderiam ser substituídos por outros que ilustrassem a tríade de virtudes que Gardner considera fundamentais na formação humana. Registro aqui uma consideração do autor sobre a importância dos valores em educação:

Não se ensina e se aprende simplesmente. Fazem-se escolhas a respeito do que ensinar, como ensinar o que foi escolhido, e por que o escolhido precisa ser ensinado e aprendido. Essas decisões são julgamentos de valor, com consequências decisivas (GARDNER, 2000, p. 79).

O autor, em educação, segue os passos de Dewey, mas não deixa de lado enfoques tradicionais se estes se mostrarem interessantes em termos de aprendizagens significativas. Gardner, já no título da obra, The Disciplined Mind, sinaliza que não deixará de lado enfoques que valorizam as disciplinas que foram se estruturando como referências de conhecimento no âmbito escolar. Ele destaca que é preciso que os alunos aprendam a pensar de maneira similar aos especialistas da área de saber estudada. Diz que não se trata de formar geógrafos mirins, físicos mirins etc. Tratase de formar pessoas capazes de entender as dimensões do saber em cada área disciplinar do currículo. Por outro lado, ele aponta como indesejável uma educação que se volta para a aprendizagem de um imenso número de fatos, com a justificativa de que é preciso cobrir extensamente a matéria estudada. Infelizmente, essa é a perspectiva hegemônica. No final do livro, na segunda edição, Gardner registra 
o debate que teve com os conteudistas, apontando que há entre ele e esses adversários um entendimento muito diferente no campo epistemológico. Para o autor, o conhecimento é construído. Para seus adversários, é acumulado. Vale observar que Gardner, nas 260 páginas de sua obra, não usa uma vez sequer a expressão aquisição de conhecimento. Pode parecer banal, mas isso é notável. Por toda parte, mesmo em ambientes que se dizem construtivistas, a dita expressão é amplamente utilizada, denunciando uma epistemologia muito difícil de ser superada.

Volto à verdade, ao belo e à bondade. A virtude da verdade, para o autor, nasce de um entendimento do que é e como se desenvolve a ciência. Mas, hoje em dia, essa perspectiva do verdadeiro sofre concorrências que é preciso considerar. O pós-modernismo, em todas as suas formas, promove um relativismo que deixa pouco espaço para a afırmação de verdades com base na ciência. Isso gera um vale-tudo epistemológico. E, mais recentemente, a noção de verdade vem sofrendo as consequências da avalanche de informações na internet. Neste último caso está a se desenvolver entendimento de que a verdade é função da frequência da informação, não importando evidências e processos de verificação.

Gardner escolheu a teoria da evolução como objeto de estudo no campo da verdade porque ela é fundamental no modo como entendemos a vida. O estudo de como Darwin articulou as evidências que foi recolhendo em suas observações ilumina entendimentos sobre o processo de busca e confirmação da verdade no campo científico. Outros temas científicos poderiam ser escolhidos, mas a teoria da evolução, na sua história, no seu desenvolvimento, nas suas consequências, é exemplar. O autor fez, no campo da beleza, a escolha de uma obra com mais de duzentos anos, mas ele argumenta que $O$ casamento de Fígaro, por sua complexidade, ilustra o grande número de aspectos que é necessário considerar no campo da arte. E a proposta de Gardner não se limita a reconhecer a ópera famosa. Ele propõe um mergulho profundo em todos os aspectos dramáticos, sociais e musicais para apreciar a obra e nela descobrir beleza. O processo seria o mesmo para outros exemplos, tanto na música como em outras artes. É preciso notar que essa indicação de embarcar na apreciação de obras de arte não é comum em propostas educacionais. Quando muito, arte é um conteúdo marginal nos currículos escolares. Entendo que, para Gardner, a educação não terá qualidade se a arte não for contemplada com a mesma profundidade que se confere à ciência e que se espera no campo da ética.

No campo da bondade, Gardner propõe um estudo profundo do Holocausto, acompanhado por julgamentos sobre noções do bem e do mal. Ele sugere um estudo profundo de um dos eventos da História recente. O saber histórico não é, per se, um capítulo da ética. Mas estudar História é uma condição necessária para formular julgamentos morais. Além disso, o estudo da História é indispensável para que se entenda como pessoas aparentemente boas se envolveram com um evento que resultou no assassinato cruel de milhões de outras pessoas. O exercício de julgamentos morais sobre eventos históricos é uma dimensão de educação que, 
esperançosamente, pode evitar crimes sociais como o Holocausto. A linha proposta por Gardner é desenvolvida por outros educadores. Um exemplo nessa direção é The Tuskegee Case, uma webquest de Tom March (EXEMPLO de WQ, 2007). Nesse material, o autor propõe o estudo de um caso famoso de discriminação racial, no qual sujeitos de um experimento sobre sífilis, todos negros, não tiveram acesso a antibióticos por decisão dos investigadores. March propõe uma pesquisa aprofundada sobre o evento, acompanhada de julgamentos morais para decidir relações com outros temas com dimensões éticas similares.

A sugestão de Gardner no campo da ética não se resume a aulas de moral, como geralmente se entende o trabalho educacional voltado para a moralidade. Ele associa ciências sociais à apreciação de suas dimensões éticas. Vale assinalar que o estudo da História, nos termos propostos pelo autor, é uma atividade exigente. 0 que se quer é que o aluno apreenda o modo de pensar dos historiadores, em vez de assimilar conteúdos previamente empacotados em materiais didáticos.

Em várias partes de sua obra, Gardner acentua a necessidade de se recomendarem estudos voltados para o aprofundamento dos temas propostos. Ele sugere que a educação deve preocupar-se com um aprofundamento vertical do que é estudado. Nesse sentido, contraria a prática comum de cobrir, nos programas de estudo, uma ampla gama de conteúdos. Essa cobertura é sempre superficial e não tem qualquer papel formativo. Com o tempo, todo o conteúdo aprendido será, felizmente, esquecido. Não se aprende uma disciplina dessa forma. A aprendizagem disciplinar exige mergulhos nos modos de fazer ciência, produzir arte e elaborar julgamentos morais.

Gardner faz várias pontes entre suas pesquisas em neurociências e a educação, além de sugerir caminhos didáticos baseados em sua teoria das múltiplas inteligências. Há um aspecto bastante relevante que quero considerar. $\mathrm{O}$ autor lembra que boa parte das crenças mais sólidas das pessoas aconteceu na primeira infância e é muito resistente a mudanças. Isso pode ser verificado nas ciências. Alunos de Física são capazes de responder a testes sobre a disciplina com bastante acerto, mas, apesar disso, não alteram suas crenças equivocadas construídas nos primeiros anos de vida sobre o mundo. O mesmo se dá em História. Em vez de desenvolver um entendimento de que os eventos históricos são multifacetados, as pessoas geralmente conservam intacta a convicção de que a História pode ser entendida como uma narrativa em que atuam mocinhos e bandidos. O mesmo vale para as convicções éticas.

O autor reconhece que há vários caminhos na construção de uma educação de qualidade, inclusive aqueles fundamentados em princípios com os quais ele não concorda. Para concretizar suas opiniões sobre educação escolar de excelência, Gardner descreve vários projetos que conhece e dos quais participa de alguma forma. Ele elenca alguns casos de projetos que utilizam como referência a teoria das inteligências múltiplas. Destaco aqui observações dele sobre as escolas de educação infantil de Reggio Emilia, região da Itália que ganhou fama internacional com um projeto para formação de crianças nos primeiros anos de vida. Gardner 
acompanha esse projeto e eventualmente com ele colabora. As escolas infantis de Reggio Emilia surgiram logo após o fim da Segunda Guerra, com a iniciativa de Loris Malaguzzi, porém a obra individual de um grande educador não explica o sucesso da educação na região. Gardner assinala que, em Reggio Emilia, há uma comunidade que sempre se compromete com empreendimentos sociais. Como já assinalei, além de propostas educacionais notáveis, as escolas infantis da região se notabilizam pela beleza arquitetônica. Além disso, as crianças podem intervir no espaço, reorganizando-o com suas obras. Depois de descrever a beleza e a riqueza do espaço dos prédios escolares de Reggio Emilia, Gardner observa:

Até agora esta descrição não diferencia as escolas de Reggio de centenas de outras escolas afluentes, atrativas [...]. As escolas de Reggio Emilia se destacam pelo tipo e qualidade das atividades que as crianças desenvolvem regularmente; se destacam também pelo profundo e respeitoso cuidado com o qual os professores interagem com as crianças e com seus pares; se destacam ainda pelo acesso gratuito à educação pública do município (GARDNER, 2000, p. 87).

Nas escolas da cidade italiana, os alunos mergulham em projetos de seu interesse, quer seja por serem inspirados por observação da natureza, quer seja por curiosidade de como funcionam artefatos tecnológicos. E o resultado de tais projetos é uma ampla produção de objetos de arte e registros do que foi observado. Gardner, após descrever as escolas de Reggio Emilia e os resultados da educação que ali acontece, observa que não fez qualquer referência às ciências da Psicologia e da Neurologia em seu relato. Os logros da famosa experiência educacional italiana são explicados pelo envolvimento dos docentes, por uma liderança inspiradora, por uma comunidade que dá importância à educação, pela cultura.

Reggio Emilia tem sido estudada com o objetivo de se reproduzir, em outras partes do mundo, o que ali se faz. Há muitas escolas que se inspiram nela em diversos países, mas o sucesso não é o mesmo, apesar de, em alguns casos, obterem-se bons resultados. Gardner explica isso dizendo que não é possível replicar inteiramente experiências de educação de qualidade. As escolas têm uma relação significativa com a história e as circunstâncias das regiões onde atuam. Para se entender as escolas de Reggio Emilia é preciso compreender a história, o povo da região, as circunstâncias sociais e políticas etc. Isso vale para muitos outros casos de educação de qualidade que podem ser encontrados mundo afora. Sempre é bom examinar tais casos como fonte de inspiração. É isso que fez, por exemplo, Mike Rose (1995) no clássico Possible Lives: The promisse of public education in America, obra que relata lindas experiências de educação pública por todo o território americano.

A ideia central na obra de Gardner é a de que a educação escolar deve estar voltada para o entendimento, a compreensão. Isso merece algumas explicações. Ciência, arte e moral (associada à História) são aprendidas por meio de disciplinas que foram se constituindo no espaço escolar historicamente. Cada uma delas oferece possibilidade de mudança para superar as noções de senso comum, profun- 
damente arraigadas nos modelos de mundo construídos nos primeiros anos de vida. É preciso mudar modos de se ver o mundo. Penso que convém recorrer ao próprio autor para explicar isso. Depois de examinar as disciplinas e dizer que elas não são um conjunto de conteúdos (matérias) que os alunos precisam apreender, Gardner esclarece:

As disciplinas não são constituídas primeiramente por fatos específicos e conceitos que aparecem nos glossários de material didático, nos compêndios de padrões nacionais, e muito frequentemente, nos testes semanais. Em vez disso as disciplinas são constituídas por maneiras de pensar, desenvolvidas por seus praticantes, permitindo que tais praticantes façam sentido do mundo de modo bastante específico e sem qualquer acento intuitivo (GARDNER, 2000, p. 155).

Gardner segue uma linha identificada muitas vezes com a Escola Nova. Ele próprio refere-se a Dewey para explicar suas convicções no campo da educação, mas não dispensa inteiramente algumas direções consideradas tradicionais. Na linha da Escola Nova e do construtivismo, ressalta a necessidade de uma educação que aprofunde verticalmente conteúdos, que seja construtivista, que não veja o conhecimento na linha do utilitarismo, mas que considere o saber por seus próprios méritos, que reforce a educação voltada para o indivíduo e que ressalte uma educação que seja pública. Ao mesmo tempo, seguindo orientações que podem ser interpretadas como tradicionais, favorece uma educação enraizada em disciplinas, que utilize regularmente instrumentos padronizados de avaliação, e que proponha altos padrões de exigência para os alunos.

Em síntese, o que é uma educação de qualidade para Gardner? A resposta está naquilo que ele propõe em termos do desenvolvimento das virtudes essenciais que todo cidadão deveria ter: compromisso com a verdade nos termos do que nos ensina a ciência, apreciação da beleza nos termos do que os artistas conseguem nos oferecer por meio de suas obras, escolha da bondade nos termos de avaliações que possam ser feitas a partir de eventos importantes da História. É um desafio exigente, mas ele pode deixar evidente um dos caminhos que vale a pena percorrer para se chegar a uma educação de qualidade.

\section{Exercício da dúvida metódica}

Ensino excelente, de Francisco de Moraes, é um exercício da dúvida metódica para abordar a educação de qualidade. O autor, como diz a Nota do Editor, revela um número muito restrito de convicções. Prefere examinar as propostas educacionais sempre com olhos de quem parte da dúvida antes de afirmar alguma certeza. Esse é um caminho interessante para evitar discursos fáticos sobre educação de qualidade. Francisco de Moraes não escreve um texto acadêmico, nem tem como referência um quadro de pesquisas pessoais sobre educação. O que faz é refletir sobre o feito, sobre sua experiência de educador em salas de aula e na gestão de instituições escolares. 
Ao relatar sua experiência pessoal, o autor vai levantando aspectos interessantes que convém ressaltar. Começo com a narrativa que ele faz de sua atuação, logo no início de carreira, como professor de escola rural. Moraes conta a história de um aluno repetente, mas esperto, inteligente e sabedor de conhecimentos sofisticados sobre a vida no campo. O autor não entendia como um aluno assim era considerado pelo sistema e pela família um caso perdido para a educação escolar. Resolveu, então, cuidar desse aluno e, no fim do ano, o menino teve um bom desempenho escolar. Francisco fica na narrativa, não elabora o acontecido em uma direção que possa sinalizar caminhos para a educação de qualidade. Ouso fazer isso a partir do caso contado. O autor, em sua prática de professor de uma escola rural, exerceu a ética do cuidado na mesma direção do que vimos na fala de Francesco Tonucci. Essa mesma ética transparece na obra de Gardner.

Um dos destaques na obra de Moraes é uma consideração sobre a relação entre quantidade e qualidade em educação. O autor aborda o tema em várias partes do livro. O trecho que se segue é uma mostra de como Moraes vê a questão:

Já afırmei que, em educação, a quantidade é condição inicial para a qualidade. A hoje laureada como saudosa, risonha e franca escola da infância dos septuagenários e outros "xxários" ainda mais antigos só pode ter sido tudo isso para alguns poucos brasileiros que sobreviveram à exclusão que deixou a maior parte pelo caminho (MORAES, 2020, p. 82).

A ponte entre essa citação e as considerações de Tonucci sobre uma escola para poucos é evidente. Um e outro autores afirmam que não há qualidade quando a educação está a serviço da pequena elite, que, por suas origens, terá sucesso garantido em uma escola feita para ela. Elite bem-educada e massa com educação precária evidenciam pouca preocupação com educação de qualidade.

Em Ensino excelente, o cuidado com a terminologia é muito grande. O autor define com precisão o que entende por ensino, aprendizagem e educação. E faz questão de distinguir muito claramente cada um desses termos dos demais. Não vou analisar as definições oferecidas, mas apenas destacar que Moraes, embora não o diga explicitamente, tenta evitar a função fática do discurso em conversas sobre educação de qualidade. Por outro lado, critica o discurso fático que aparece na legislação educacional e nos documentos que a regulamentam. Ao fazer referência à Lei de Diretrizes e Bases da Educação Nacional (LDB), Moraes nota que ela é recheada de remendos, em tentativas de incluir opiniões divergentes. O resultado concilia as diferenças, mas esvazia o significado do que se propõe. Falseia-se, no caso, o que é qualidade. Recorro mais uma vez ao autor para deixar claro o aspecto em foco:

Entretanto essa boa qualidade tem como contraponto seu hermetismo que ainda tenta conciliar correntes divergentes, fenômeno que o torna quase inócuo na prática cotidiana das escolas, dos professores e dos estudantes (MORAES, 2020, p. 54). 
Preocupações terminológicas podem parecer exageradas, porém são fundamentais para que os objetivos do ensino e da educação fiquem claros, permitindo medidas de avaliação que possam aferir qualidade. Na obra toda, Moraes insiste nesse ponto. $\mathrm{O}$ autor defende a ideia de que a qualidade da educação deve ser medida pelos resultados da aprendizagem. Nessa direção, parece que ele relativiza discussões sobre qualidade centrada no ensino. Esse ponto de vista oferece direções muito claras e objetivas para se falar sobre qualidade. Por outro lado, ele pode deixar de lado discussões sobre qualidade voltadas para as condições de oferta de educação, compreendendo o ambiente que pode favorecer aprendizagens significativas. Vimos, na apreciação do livro de Gardner, que o sucesso de Reggio Emilia tem muito a ver com as condições de ensino, incluída aí a arquitetura escolar. Moraes não desconhece a importância das condições favoráveis à aprendizagem. Em algumas partes de seu livro, narra episódios em que detalhes do ambiente de aprendizagem revelam preocupação com a qualidade.

Francisco de Moraes passou boa arte de sua vida de educador em instituições de educação profissional. Essa experiência mostrou-lhe a importância do saber manual, e ao abordar o tema ele lembra que a mão educa o cérebro. Isso pode parecer um detalhe ligado à biografia do autor, no entanto é preciso lembrar que outro educador, Francesco Tonucci, com experiências bem diferentes, faz uma crítica ao desaparecimento do saber manual nos níveis mais avançados da educação escolar. Em uma educação de qualidade, as mãos não podem ser esquecidas.

Nos meios de comunicação, ganham importância registros dos resultados obtidos por estudantes em testes padronizados, nacionais e internacionais. Esses resultados costumam ser analisados por meio de estatística descritiva, com a revelação de tendências e o estabelecimento de vários tipos de comparação entre países, sistemas escolares e escolas. Moraes analisa o fenômeno e nota que esses resultados de estatística descritiva acabam dando origem a rankings que são utilizados para indicar qualidade da educação nos níveis internacional, nacional e local. 0 autor mostra que essa forma de considerar qualidade é equivocada. Ela, entre outras coisas, deixa de lado inteiramente a qualidade das condições de ensino. Convém lembrar que Moraes destaca que a quantidade é uma das funções da qualidade. Rankings assinalam geralmente o sucesso de escolas de elite, que excluem estudantes das classes populares. Eles, na verdade, qualquer que seja a comparação feita, privilegiam uma educação de qualidade duvidosa mesmo nas escolas mais bem ranqueadas.

A intenção de Francisco de Moraes foi escrever uma obra que destacasse a gestão como fator de qualidade da educação, no entanto ele não escreve um livro de administração escolar, e sim uma obra analítica sobre educação, introduzindo as questões de gestão em suas relações com os objetivos educacionais, qualidade do ensino e resultados de aprendizagem. Escreve um livro de educação, não de administração. 


\section{Onde está a qualidade?}

Para o espaço de que disponho aqui, não pude fazer uma apreciação bem apurada das obras que escolhi, mas penso que consegui elencar alguns aspectos que é preciso considerar quando se fala em educação de qualidade. Os três autores destacam a ética do cuidado como orientação fundamental para a existência de uma educação de qualidade. Essa ética exige inclusão de todos. Exige oferta de educação que não se limite a completar o saber que os alunos receberam em casa, pois muitos estudantes chegam à escola sem qualquer capital cultural.

Resultados de aprendizagem são importantes, mas não bastam. As medidas utilizadas podem aferir apenas apreensão de conteúdo, e não entendimento profundo do assunto nos termos propostos por Gardner. Isso nos leva a pensar no tipo de epistemologia que é pressuposto da atividade educadora. A perspectiva cumulativa de saber que se apreende em um extenso programa escolar, mesmo que produza resultados de aprendizagem notáveis, é de qualidade duvidosa. Já sabemos, a partir da revolução da ciência cognitiva, lembrada por Gardner, que educação de qualidade resulta de processos pessoais de construção do conhecimento. Os três autores manifestam esse entendimento em suas obras.

A resposta para a pergunta que abre esta seção pode incluir um grande número de indicações sobre qualidade. E é possível encontrar tais indicações nos três autores cujas obras foram aqui resenhadas, mas podemos nos contentar com algumas indicações mais expressivas. Como já destaquei, a qualidade está no cuidado. Está na inclusão, que não só traz para a escola todas as crianças, mas não deixa qualquer delas para trás. Está na gestão de lideranças sintonizadas com a comunidade local e com sua cultura, necessidades e sonhos.

\section{Referências}

EXEMPLO de WQ. In: OFICINA WEBQUEST. [S. I.: s. n.], 15 ago. 2007. Disponível em: https://jarbasquest.wordpress.com/exemplo-de-wq/. Acesso em: 28 nov. 2020.

GARDNER, Howard. The disciplined mind: beyond facts and standardized tests K-12 education that every child deserves. New York, Penguin Books, 2000.

LEECH, Geoffrey. Semántica. Madrid: Alianza Editorial, 1977.

MORAES, Francisco de. Ensino excelente: anotações e comentários para estudantes, pais e educadores. São Paulo: Editora Senac São Paulo, 2020.

ROSE, Mike. Possible lives: the promisse of public educaction in America. New York; Penguin Books, 1995. 
TONUCCI, Francesco. ¿CÓMO puede ser la escuela para el mañana? Granada: Parque de las Ciencias de Granada, 20 fev. 2012. 1 vídeo (80 min.). Disponível em: https://www.youtube.com/watch?v=caS8XeuCPFA. Acesso em: 10 dez. 2020.

Jarbas Novelino Barato. Professor. Doutor em Educação pela Universidade Estadual de Campinas (Unicamp). Mestre em Tecnologia Educacional pela San Diego State University (SDSU). E-mail: jarbas.barato@gmail.com 